\title{
A FILOSOFIA E 0 SEU ENSINO SOB O DIAPASÃO DA CRIATIVIDADE
}

\author{
Victor Hugo de Oliveira Saldanha'
}

RESUMO: O presente artigo tem o propósito de abordar a filosofia na perspectiva de sua definição e de seu ensino, especificamente no domínio na educação básica. A abordagem ora proposta organiza-se numa estrutura tripartite: na primeira parte, pretende-se tecer algumas considerações preambulares à questão "o que é a filosofia?" e, em seguida, traçar dois requisitos fundamentais para uma possível resposta a esta interrogação. A segunda parte apresenta a definição deleuzo-guattariana da filosofia como "a arte de criar conceitos" e assinala a centralidade do conceito e do problema na caracterização da atividade filosófica. À vista da definição deleuzo-guattariana da filosofia como uma atividade per se criativa, definição que descortina o problema do ensino criativo dessa disciplina, a terceira parte sugere como possibilidade do exercício da criatividade no ensino médio a proposta do filósofo Silvio Gallo de compreender a aula de filosofia como uma oficina de conceitos.

PALAVRAS-CHAVE: Filosofia; Conceito; Problema; Criatividade; Ensino. 


\begin{abstract}
This article aims to address the philosophy from the perspective of its definition and its teaching, particularly in the area in basic education. The approach proposed here thread through three distinct stages: first, we intend to make a few remarks to introduce the question "what is philosophy?" And then sketch two fundamental characteristics for a possible answer to this question. The second stage intends to expose the definition of Deleuze and Guattari's philosophy as "the art of creating concepts" and present the centrality of the concept and the problem in the characterization of philosophical activity. From the Deleuze-Guattarian definition of philosophy as a per se creative activity, setting that reveals the problem of creative teaching of this discipline, the third stage suggests the idea of the philosopher Silvio Gallo to understand the philosophy class as concepts workshop as possibility of creativity exercise in basic education.
\end{abstract}

KEYWORDS: Philosophy. Concept; Problem; Creativity; Education. 


\section{CONSIDERAÇÕES PRELIMINARES ACERCA DA QUESTÃO O QUEÉ A FILOSOFIA?}

Não se pode objetar que toda reflexão acerca de conteúdos, metodologias e estratégias para o ensino da filosofia, sobretudo no ensino médio, onde vige a obrigatoriedade dessa disciplina na grade curricular, perpassa a questão "o que é a filosofia?". Sobre essa questão, Deleuze e Guattari declaram:

É uma questão que enfrentamos numa agitação discreta, à meia-noite, quando nada mais resta a perguntar. Antigamente nós a formulávamos, não deixávamos de formulá-la, mas de maneira muito indireta ou oblíqua, demasiadamente artificial, abstrata demais [...]. Tínhamos muita vontade de fazer filosofia, não nos perguntávamos o que ela era, salvo por exercício de estilo; não tínhamos atingido este ponto de nãoestilo em que se pode dizer enfim: mas o que é isto que fiz toda a minha vida? (DELEUZE; GUATTARI, 1992, p.9).

A propositura de tal questão demanda, inexoravelmente, de seu respondedor a explicitação da especificidade da atividade filosófica, ou seja, daquilo que singulariza a filosofia em meio aos demais saberes. Em linguagem filosófica, essa interrogação exprime a necessidade de pôr a descoberto a definição ou a essência da filosofia, que se expressa eminentemente pela pergunta filosófica “o que é?"2. 
No texto Qu'est-ce que la philosophie? Heidegger (2005) afirma que de há muito caracteriza-se a pergunta pelo que algo é como a questão da essência; e tal questão "torna-se mais viva quando aquilo por cuja essência se interroga se obscurece e confunde, quando a relação do homem para com o que é questionado se mostra vacilante e abalada" (HEIDEGGER, 2005, p.31). Assim, tanto mais a filosofia se torna problemática, obscura ou até mesmo malquista para o homem contemporâneo, mais a questão "o que é a filosofia?" torna-se vivaz e urge ser respondida. A consecução dessa resposta talvez possa oferecer um critério por meio do qual seja possível determinar, ainda que sumariamente, o porquê da relação do homem com a filosofia se ter tornado problemática ou, ainda, o porquê da aparente crise da filosofia na contemporaneidade ${ }^{3}$.

Responder à questão "o que é a filosofia?", isto é, delinear suas características substanciais, seu modo de operação, sua finalidade específica, seu objeto próprio - na hipótese de haver um objeto que lhe seja próprio - e a circunscrição do seu campo de atividade, não se afigura uma empresa simples, nem tampouco unívoca. A plurivocidade dessa questão é claramente atestada pelos vários modos com que os filósofos conceberam este problema, desde a antiguidade clássica até a contemporaneidade, e pela diversidade de definições para o termo "filosofia" se seguiu dessa compreensão plurívoca do problema. Inobstante a essas diversas definições de que a seara filosófica já dispõe, é possível que atribuir uma definição para a filosofia seja um problema subjacente e anterior a todos os outros problemas filosóficos; trata-se, 
talvez, de responder antes de tudo à questão "o que é isso por meio do qual se tematizou, no decurso de mais de dois milênios, os problemas que concernem ao ser, à virtude, à felicidade, ao conhecimento e à política?". Nada obsta que tal pergunta ainda seja tão atual quanto premente e que ainda permaneça nos nossos tempos como um problema filosófico não superado.

Se, por um lado, não se afigura contra a razão prestar anuência à compreensão heideggeriana de que a resposta procurada não deva ser meramente discursiva (HEIDEGGER, 2005), por outro, parece ser igualmente razoável consentir que determinar a natureza da filosofia deva ser, em si mesmo, uma atitude de natureza filosófica, afinal, a própria interrogação "o que é?" (ti estin) já carrega consigo um caráter marcadamente filosófico ${ }^{4}$. Acerca do estatuto filosófico não só da maneira de se interrogar, mas também da maneira de se retorquir à pergunta "o que é a filosofia?", Heidegger (2005, p.34-35) pontifica que a resposta a essa questão "[...] somente pode ser uma resposta filosofante, uma resposta que enquanto resposta filosofa por ela mesma”. Logo, a solução para o problema proposto não deve ser procurada ou construída alhures, mas no interior da própria filosofia, constituindo-se, assim, uma resposta de natureza estritamente filosófica.

Ora, se se aquiesce que definir a filosofia seja em si mesmo um problema filosófico que demanda uma réplica igualmente filosófica (tal como proposto nos parágrafos acima), deve-se também aquiescer que a definir seja uma atitude de natureza tal que admita diversas possibilidades de enfrentamento do problema "o que é a filosofia?" e, a 
fortiori, uma diversidade de respostas ou definições, pois não é desejável que um problema filosófico seja coarctado, inflexivelmente, a um único prisma. Com efeito, posto que a formulação de uma definição para a filosofia está condicionada tanto pelas potencialidades e limitações de quem se abalança a defini-la, quanto pelas variáveis históricas e culturais, é eminentemente improvável que de tamanha diversidade entre pessoas, épocas e culturas resulte apenas uma única definição ou que, dentre várias, apenas uma deva ser considerada a correta. Assim, resulta evidente que qualquer pretensa definição para a filosofia deve se apresentar de maneira contingente, quer dizer, deve admitir sua coexistência com outras possíveis definições ou, simplesmente, deve entender a si mesma com uma possibilidade entre outras.

Ao fim e ao cabo, as considerações aduzidas na primeira parte deste estudo conduzem à hipótese de que uma boa resposta para a questão "o que é a filosofia?" deve afigurar-se, preferencialmente, como uma resposta filosófica e contingencial. Ademais, considerando que esse último aspecto, o caráter contingencial, implica a admissibilidade de uma pluralidade de respostas, isto é, de definições para a filosofia, pode-se também corroborar a legitimidade da competência de cada filosofia e cada filósofo para determinar o que é que se entende por filosofia, uma vez que tal determinação implica já uma filosofia (GOUHIER, 1947). Por isso, o presente estudo não tem o fito de propor uma definição que vindique nem o caráter da necessidade, nem o da universalidade; 
ao invés, pretende sugerir uma definição para a filosofia como uma dentre outras possíveis.

\title{
II. A DEFINIÇÃO DELEUZO-GUATTARIANA: A FILOSOFIA COMO A ARTE DE CRIAR CONCEITOS
}

\begin{abstract}
À vista da vivacidade da interrogação atinente à essência da filosofia - expressa pela pergunta "o que é?" - e da pluralidade possível das respostas a essa interrogação, a segunda parte do estudo ora proposto intenta apresentar uma resposta ao problema em questão. Logo nas páginas iniciais da obra O que é a Filosofia? (1992), Deleuze e Guattari (1992, p.10) propõem uma definição clara e precisa para o objeto investigado: "a filosofia é a arte de inventar, de formar, de fabricar conceitos". Consoante a essa definição proposta pelos autores franceses, o cânone da filosofia é, portanto, a criatividade; sua especificidade, o trabalho com o conceito; e o filósofo, que possui o conceito em potência, o responsável por essa atividade criadora.
\end{abstract}

A filosofia, mais rigorosamente, é a disciplina que consiste em criar conceitos [...]. Criar conceitos sempre novos é o objetivo da filosofia. É porque o conceito deve ser criado que ele remete ao filósofo como aquele que o tem em potência, ou que tem sua potência e sua competência [...]. Que valeria um filósofo do qual se poderia dizer: ele não criou seus conceitos? (DELEUZE; GUATTARI, 1992, p.13-14). 
Tendo conferido ao ato de criar novos conceitos o estatuto de característica definidora da filosofia, os autores franceses empreendem no primeiro capítulo da obra supramencionada uma descrição detalhada da ideia de conceito. Ora, se a atividade filosófica corresponde à criação de conceitos, não teria, então, uma relevância capital determinar não só o que é propriamente um conceito, mas também as condições que possibilitam a sua criação? Por isso, faz-se mister passar à exposição desses dois aspectos fundamentais: a natureza do conceito e a condição de possibilidade da sua criação pelo filósofo, conforme a perspectiva deleuzo-guattariana.

Silvio Gallo, leitor de Deleuze e Guattari, explica, citando Merleau-Ponty, a acepção de conceito proposta pelos autores franceses:

Podemos definir o conceito como sendo uma aventura do pensamento que institui um acontecimento, vários acontecimentos, que permita um ponto de visada sobre o mundo, sobre o vivido. Poderíamos, aqui, lembrar a célebre afirmação de Merleau-Ponty: "a verdadeira filosofia consiste em reaprender a ver o mundo"; parece ser disso que falam Deleuze e Guattari quando exprimem a ação do conceito: um reaprendizado do vivido, uma ressignificação do mundo. [...] O conceito é como um sobrevoo (essa imagem é reincidente em Deleuze: o conceito como um pássaro que sobrevoa o vivido...). [...] É por isso que o conceito é exclusivamente filosófico (GALLO, 2010, p.54, grifo do autor). 
No percurso argumentativo que forja a noção de conceito como sobrevoo, reaprendizado do mundo vivido e instituição de um acontecimento, conforme aduzido por Silvio Gallo, os pensadores franceses expõem várias outras características distintivas de um conceito, quais sejam, sua história, multiplicidade, incorporeidade, absolutidade, relatividade etc.

Todo conceito possui uma história, não sendo "jamais", afirmam Deleuze e Guattari (1992, p.31), "criados do nada”; um conceito é sempre produto de e composto por outros conceitos ou por outras fontes não filosóficas já constituídas historicamente. Por via de consequência, o conceito também é múltiplo, pois é formado pela conjunção de várias fontes e elementos (filosóficos ou não), inobstante tudo isso se encontre totalizado e sintetizado numa unidade conceitual. Em virtude disso, todo conceito se apresenta sempre como um "[...] todo fragmentado, como um caleidoscópio, onde a multiplicidade gera novas totalidades provisórias a cada golpe de mão" (GALLO, 2010, p.55). Enfim, visto que os autores definem o conceito de maneira muito mais ampla na obra $O$ que é a Filosofia?, optar-se-á, neste estudo, apenas por esta exposição sumária da acepção deleuzoguattariana do conceito, a fim de passar ao exame da sua condição de possibilidade, isto é, daquilo que se constitui como o ponto de partida para a criação de todo conceito, a saber: um problema.

Segundo Deleuze e Guattari, todo conceito remete a um ou a vários problemas, seja a problemas novos, seja a problemas antigos considerados como mal explicitados ou 
mal respondidos; a problemas sem os quais o conceito seria destituído de todo e qualquer sentido.

Dito de outro modo, diferentemente das ciências, cujo sentido consiste na aquisição de um conjunto de verdades que responda às questões relativas ao seu objeto de estudo, a filosofia tem o seu sentido assegurado não tanto pelas respostas que fornece aos problemas por sobre os quais se debruça, mas, primordialmente, pela formulação e pela clara exposição dos problemas em si mesmos.

Os problemas garantem não só a significação da atividade filosófica, mas também a sua própria existência, uma vez que eles "[...] abrem um horizonte de sentido, e que subtendem a criação de conceitos", conforme elucida Zourabichvili (2004, p.48) em seu Vocabulário de Deleuze (2004). Por isso, para Deleuze e Guattari, o conceito é, a um só tempo, absoluto e relativo; por um lado, é "relativo aos problemas aos quais se dirige" e, por outro, "adquire ar de absoluto, pois condensa uma possibilidade de resposta ao problema" (GALLO, 2010, p.56).

Considerando, pois, tamanha relevância do problema para a garantia do sentido da filosofia, não seria contra a razão interrogar-se se não poderia essa demasiada valorização do problema na investigação filosófica ter sido a responsável pela filosofia haver auferido menos sucesso que as ciências na empresa de obter respostas definitivas para as suas questões, de modo que isso (a demasiada valorização da perspectiva do problema) pudesse ter levado a filosofia a se deter excessivamente aos problemas, por sobrestimá-los, e a descurar do devido interesse às respostas, por oposição às ciências, sempre ávidas por 
responder. Na obra Os Problemas da Filosofia (2005), Russell estabelece uma comparação entre a filosofia e as ciências no que se refere à eficácia na consecução de respostas definitivas para seus problemas, dizendo:

[...] não se pode dizer, no entanto, que a filosofia tenha tido algum êxito na sua tentativa de dar respostas definitivas às suas questões. Se perguntarmos a um matemático, a um mineralogista, a um historiador, ou qualquer outro homem de saber, que conjunto de verdades concretas foi estabelecido pela sua ciência, sua resposta durará tanto tempo quanto estivermos dispostos a lhe dar ouvidos. Mas se fizermos essa pergunta a um filósofo, terá que confessar, se for sincero, que a filosofia não alcançou resultados positivos como os que foram alcançados por outras ciências (RUSSELL, 2005, p.172-173).

Encontra-se, ainda na obra russelliana, uma possibilidade de resposta à problemática assinalada acima. Nessa obra, Russell (2005) afirma que não pode ser atribuído à filosofia um conjunto de verdades definitivas porque tão logo, no curso da investigação filosófica, um conjunto de conhecimentos acerca de um dado objeto torna-se seguro e se consolida, este conjunto já não pode mais ser chamado filosofia, porquanto se torna uma ciência específica.

Com base nessa afirmação russelliana, conclui-se, por um lado, que nos é permitido dizer com considerável margem de acerto que a perspectiva do problema é, incontestavelmente, fundamental para a caracterização atividade filosófica, mas, por outro, nos é interdito afirmar que disso se segue 
a secundarização ou a marginalização do interesse pelas respostas - o que poderia ser a causa da filosofia não ter obtido tanto êxito na consecução de respostas definitivas para seus problemas se comparada com as ciências. Conforme a asserção russelliana mencionada acima, embora não se possa atribuir à filosofia um corpo de verdades universais e definitivas, não é verdade que a filosofia só tenha auferido de suas investigações respostas incertas e provisórias, e nunca conhecimentos sólidos e definitivos; o fato é que esses conhecimentos, tão logo foram constituídos, se emanciparam da filosofia, tornando-se uma ciência particular. Nesse sentido, a filosofia poderia ser compreendida como uma espécie de maiêutica, cujo mister consistiria, em última análise, em trazer a lume os diversos conhecimentos a que chamamos ciência. Segundo Russell (2005), isso explica, em parte, a acusação imputada à filosofia no que tange à sua aparente impotência para a obtenção de respostas sólidas aos seus problemas, como se observa na passagem abaixo:

Todo estudo dos corpos celestes, que hoje pertence à astronomia, incluía-se outrora na filosofia; a grande obra de Newton tem por título: "Princípios matemáticos da filosofia natural". De maneira semelhante, o estudo da mente humana, que fazia parte da filosofia, está hoje separado da filosofia e tornou-se a ciência da psicologia. Desse modo, a incerteza da filosofia é, em grande medida, mais aparente que real: os problemas para os quais já se tem respostas positivas vão sendo colocados nas ciências, enquanto que aqueles para os quais não se encontrou até hoje nenhuma resposta 
exata, continuam a constituir esse resíduo que denominamos de filosofia (RUSSELL, 2005, p.173).

Aos exemplos fornecidos pelo filósofo britânico poderse-ia acrescentar ainda o estudo do conhecimento, que noutros tempos era empreendido nos domínios da filosofia e hoje tornou-se epistemologia. Em suma, de acordo com Russell (2005), não se denomina filosofia senão ao conjunto de problemas e interrogações que permanecem irrespondidos de todo ou respondidos, mas de maneira muito geral e insuficiente.

Em resumo, a identificação de um problema, sua interpretação e possível resolução - ainda que provisória - por meio de conceitos caracterizam fundamentalmente a filosofia, ao passo que a posse de um conjunto de respostas e de conhecimentos definidos sobre um determinado objeto constitui - ou, ao menos, deveria constituir - o domínio das ciências. Disso decorre que não compete à filosofia, muito embora ela não seja de todo incapaz de fazê-lo, o enunciado de respostas definitivas em assuntos de qualquer matéria, pois a finalidade da atividade filosófica é destacar, conceitualmente, o acontecimento das coisas e dos seres (DELEUZE; GUATTARI, 1992), e o acontecimento é sempre singular, nunca universal; ressignificado, jamais definido.

À vista do exposto até aqui, isto é, da apresentação de uma possibilidade de definição para a filosofia (a arte de criar conceitos) e da explicitação dos caracteres fundamentais da atividade filosófica (o conceito e o problema), fica-se em condições de pontuar a discussão 
proposta na primeira parte acerca dos motivos pelos quais a filosofia possa ter se tornado problemática ou porque ela atravessa um momento de crise, ao menos aparente, na contemporaneidade.

Na perspectiva de Deleuze e Guattari (1992), a filosofia, a quem compete por princípio a criação de novos conceitos, cruzou, recentemente, com vários obstáculos, como a sociologia e a voga epistemologia, da linguística e da psicanálise; porém, os pensadores franceses apontam como o principal óbice para a filosofia na contemporaneidade a tomada do conceito e da prerrogativa de criá-lo pelo marketing, pelo design, pela publicidade e, de modo geral, pelas disciplinas da comunicação. A partir dessa tomada, o conceito encontrou-se submetido ao comércio de tal modo que, nos dias atuais, se afigura impossível lançar um breve olhar à realidade circundante e não constatar, sem grande esforço, expressões como "um novo conceito de imóvel", "um novo conceito de eletrodoméstico", "um novo conceito de automóvel" e outras similares. Desde que o marketing se apropriou da ideia de uma certa relação entre o conceito e o acontecimento, declaram Deleuze e Guattari (1992, p.19), "o conceito tornou-se o conjunto das apresentações de um produto [...] e o acontecimento, a exposição que põe em cena apresentações diversas e a 'troca de ideias' à qual supostamente dá lugar”.

O simulacro, a simulação de um pacote de macarrão tornou-se o verdadeiro conceito, e o apresentador- 
expositor do produto, mercadoria ou obra de arte, tornou-se o filósofo, o personagem conceitual ou o artista [...]. Certamente, é doloroso descobrir que o "conceito" designa uma sociedade de serviços e de engenharia informática (DELEUZE; GUATTARI, 1992, p. 19).

Tendo, pois, proposto uma resposta para a questão “o que é a filosofia?", delineado dois aspectos centrais para a caracterização da atividade filosófica e aduzido a interpretação deleuzo-guattariana da aparente crise da filosofia na contemporaneidade, faz-se necessário retornar à definição da filosofia como "a arte de formar, inventar e fabricar conceitos" (logo, como uma atividade essencialmente criativa), pois é esta definição que descerra um novo eixo problemático para o presente estudo; eixo este que se relaciona não mais com a definição da filosofia, mas com o seu ensino, a saber: se a filosofia é, por excelência, uma atividade de caráter criativo, por que não sê-lo-ia também o seu ensino de natureza criativa? Ora, é impossível pensar os domínios da prática filosófica propriamente dita e do ensino da filosofia como domínios totalmente disjuntos; portanto, é razoável que haja uma intersecção, do ponto de vista da criatividade, entre os domínios do ensino e do fazer filosófico. E é, precisamente, à possibilidade desta intersecção, isto é, à possibilidade de conceber o ensino da filosofia como algo criativo, que se consagra a última parte deste estudo. 


\section{A AULA DE FILOSOFIA COMO OFICINA DE CONCEITOS: UMA POSSIBILIDADE DO EXERCÍCIO DA CRIATIVIDADE NO ENSINO MÉDIO}

Pensar a filosofia no contexto escolar desvela quase automaticamente uma série de questões que, não obstante venham se tornando cada vez mais recalcadas, permanecem ainda relevantes e em aberto, pois que não se pode dizer que já foram respondidas peremptoriamente. Renata Pereira de Lima Aspis pontua algumas dessas questões:

É possível que o professor pense: para que defender a filosofia na escola? O que há de específico na filosofia que a faz necessária no currículo dos jovens? Qual filosofia ensinar? Como fazê-lo? Damos aulas de filosofia ou de filosofar? É possível uma separação das duas coisas? (ASPIS, 2004, p.306).

Em suma, pode-se condensar em três aquelas questões inobliteráveis das reflexões de um professor de filosofia: (i) o que é a filosofia?; (ii) se ela pode ser ensinada, como fazê-lo?; e, por último, (iii) por que ela deve estar presente no ensino médio? Tendo dedicado as duas primeiras partes deste estudo ao exame da primeira questão, urge avançar à segunda, que pela grandeza do horizonte de reflexões que enseja obriga-nos a pôr de parte a terceira. Destarte, o último momento desta reflexão acerca da filosofia e do seu ensino tenciona apresentar uma sugestão para o ensino da filosofia na educação básica, de maneira que este ensino 
não negligencie o estatuto de criatividade que é essencial à filosofia. Para levar a cabo este desiderato, propõe-se uma incursão no pensamento do filósofo Silvio Gallo, que, radicado na definição deleuzo-guattariana da filosofia, sugere conceber a aula de filosofia como uma oficina de conceitos. Essa proposta é sistematizada, brevemente, pelo filósofo brasileiro em quatro passos didáticos, à cuja exposição se dedicarão os parágrafos seguintes.

No entanto, antes passar à exposição da proposta de Silvio Gallo, faz-se necessário empreender uma digressão sucinta com o fito de assinalar (não responder) uma questão recorrente nas discussões sobre o ensino da filosofia na educação básica: o papel a ser desempenhado pela história da filosofia.

In limine, não se pode examinar a questão do ensino da filosofia sem se remeter à afamada passagem da Crítica da Razão Pura (2013) em que Kant assevera não ser possível aprender a filosofia ${ }^{5}$, mas tão somente a filosofar. Como se observa no excerto a seguir, o filósofo alemão entende não ser possível aprender a filosofia senão historicamente.

Entre todas as ciências racionais (a priori) só é possível, por conseguinte, aprender a matemática, mas nunca a filosofia (a não ser historicamente) [...]. Até então não se pode aprender nenhuma filosofia; pois onde está ela? Quem a possui? Por que caracteres se pode conhecer? Pode-se apenas aprender a filosofar, isto é, a exercer o talento da razão na aplicação dos seus princípios gerais em certas tentativas que se 
apresentam, mas sempre com a reserva do direito que a razão tem de procurar esses próprios princípios nas suas fontes e confirmá-los ou rejeitá-los (KANT, 2013, p. 672-673).

Trazendo a afirmação kantiana de que só se pode aprender a filosofia historicamente para o fio argumentativo seguido na presente investigação e considerando tal afirmação segundo a definição deleuzo-guattariana da filosofia, é possível supor, em alguma medida, que a inserção na atividade filosófica requer o diálogo com aqueles que também já filosofaram no curso da história, pois os conceitos filosóficos não são criados ex nihilo, ao contrário, todo conceito remete a outros conceitos, tanto em seu devir e em suas conexões, quanto em sua história (DELEUZE; GUATTARI, 1992). Por isso, alguns afirmam que o aspecto histórico tem lugar não só importante, mas indispensável no processo do ensino da filosofia, na medida em que ele situa o aluno em um debate construído graças à contribuição de diversos filósofos no transcurso da história. Silvio Gallo (2006), por exemplo, reconhece a necessidade de que os alunos conheçam a história da filosofia para que possam aprender o ato de filosofar ${ }^{6}$.

No que concerne ao problema relativo ao papel da perspectiva histórica no ensino da filosofia, pode-se legitimamente indagar se aquela interpretação que destaca a necessidade da história da filosofia coaduna com o pensamento dos autores franceses, que parecem tender a atribuí-la um papel negativo. A esse respeito, Jeferson Luis 
de Azeredo (2011, p.46) ressalta que, em Deleuze, "a noção de história da Filosofia não tende a ser um controle, uma forma de intimidação que venha a estabelecer fronteiras ou que sirva de contraposição ao pensado".

Nesse sentido, Azeredo analisa a concepção de Deleuze sobre o papel a ser desempenhado pela história da filosofia no ensino dessa disciplina, nos seguintes termos:

Deleuze [...] já condenava em sua época as escolas e centros universitários que trabalhavam com uma noção de história da Filosofia com papel limitador à criação, pois exigiam ao estudante uma gama de conhecimentos ligados à história antes de os possibilitarem o poder de pensar. É importante lembrar que, para Deleuze, a criação não antevém à história, mas há entre elas uma dependência mútua; uma é necessária a outra. Só que não é uma história que limita e sim que abre o estudante à multiplicidade, a variações múltiplas, igualmente não é uma filosofia controlada que vai traçando a história (AZEREDO, 2001, p.46).

No contexto da discussão atinente à necessidade do emprego da perspectiva histórica no ensino da filosofia, uma posição mais moderada preconiza que pensar o ensino dessa disciplina na educação básica exige esforçar-se por determinar os limites do uso da história da filosofia a fim de evitar os extremos do excesso e da falta. Conforme essa visão, os professores devem, seguramente, cuidar para não incorrer no extremo da falta, pois "[...] ensinar filosofia 
é também ensinar história da filosofia" (GALLO, 2006, p.18, grifo do autor); e devem evitar, outrossim, o extremo do excesso, a fim de não recair no que Gallo denomina "conteudismo", isto é, tomar a aula de filosofia como uma mera transmissão de conteúdos historicamente produzidos, o que acarretaria a perda do “[...] desenvolvimento da experiência filosófica como prática do pensamento” (GALLO, 2006, p.19).

Malgrado às dissidências no tocante à interpretação da necessidade ou do papel a ser desempenhado pelo aspecto histórico no ensino da filosofia no contexto da educação básica (sobretudo se se leva em consideração o pensamento de Deleuze e Guattari), afigura-se sempre indispensável pontuar tal questão, entretanto, convém deixá-la em aberto (já que respondê-la não constitui a finalidade deste estudo) e retornar ao objeto desta terceira parte: o ensino criativo da filosofia.

Se, por um lado, Silvio Gallo considera o contato com a história da filosofia a conditio sine qua non para que se aprenda a filosofar, por outro, o filósofo brasileiro (2006) assevera ser necessário uma ruptura com a tradição para que possa irromper o novo, afinal, criar conceitos sempre novos é o propósito essencial da filosofia (DELEUZE; GUATTARI, 1992). Destarte, se a filosofia é concebida pelo professor como uma atividade per se criativa, então este deve, necessariamente, adaptar a aula ao estatuto do seu objeto (a filosofia) e balizar suas estratégias e metodologias pelo critério da criatividade. À vista disso, é forçoso que uma aula de filosofia assim concebida não se adequará, 
de nenhuma maneira, aos modelos de aula comumente estabelecidos, os quais Silvio Gallo esboça:

[...] aquela [aula] que enfatiza o caráter dialógico, colocando todos os alunos "em círculo", para possibilitar o diálogo em pé de igualdade; aquela que enfatiza o debate, e não raro não chega a sair de uma espécie de "arena de opiniões"; aquela em que o professor traz notícias "fresquinhas" de jornal para serem analisadas e debatidas, enfatizando o sentido do cidadão que participa de sua comunidade; aquela que adquire um "tom enciclopédico", na medida em que o professor vai fazendo desfilar frente aos estudantes uma galeria de filósofos e/ou sistemas filosóficos, articulados ou não segundo uma cronologia histórica; aquela em que o professor desenvolve análise e comentário de textos filosóficos (GALLO, 2006, p.25).

Em oposição aos modelos supracitados, Gallo (2006, p.25) propõe conceber a aula como uma espécie de oficina de conceitos, enfatizando que se se toma por pressuposto a definição da filosofia proposta por Deleuze e Guattari, então a aula de filosofia "[...] precisa adquirir um caráter prático, investigativo, dinâmico, sem, no entanto, cair no senso comum e no 'opinionismo', sem perder a dimensão estritamente filosófica do conceito". Citando Deleuze e Guattari, Silvio Gallo explica a proposta de tornar a aula de filosofia uma oficina de conceitos:

Falar em oficina de conceitos é falar em experimentação, que remete ao novo, à criação: "pensar é experimentar, 
mas a experimentação é sempre o que se está fazendo - o novo, o notável, o interessante, que substituem a aparência de verdade e que são mais exigentes que ela." (Deleuze; Guattari, 1992, p. 143). Por isso, numa aula de filosofia assim concebida importa mais o processo criativo, a experimentação, fazer o movimento de pensamento, do que o ponto de chegada, a solução do problema, a veracidade do conceito criado. Importa que cada estudante possa passar pela experiência de pensar filosoficamente, de lidar com conceitos criados na história, apropriar-se deles, compreendê-los, recriálos e, quem sabe, chegar mesmo a criar conceitos próprios (GALLO, 2006, p.26).

O filósofo brasileiro sistematiza didaticamente as etapas de trabalho de uma oficina de conceitos em quatro passos: 1) sensibilização; 2) problematização; 3) investigação;4) conceituação.

A primeira etapa desse processo, a sensibilização, visa suscitar a empatia do aluno com um tema determinado; nas palavras de Gallo (2006, p.27), "trata-se [...] de fazer com que os estudantes vivam, 'sintam na pele', um problema filosófico, a partir de um elemento não filosófico". No texto Ensi(g)nar Filosofia? (2004), Rui Grácio e Sousa Dias apresentam um ponto de vista semelhante a esse respeito.

Segundo Grácio de Dias (2004), é preciso, antes de tudo, considerar que os destinatários do ensino escolar da filosofia são jovens cujos interesses, assaz modelados pela tecnocultura, não são apenas pré-filosóficos, mas antifilosóficos, de maneira que nada neles pede filosofia. Em virtude disso, os autores portugueses sugerem a 
necessidade de se induzir o filosófico pelo não-filosófico, ou seja, de se partir do pré-filosófico ou do não-filosófico a fim de conduzir os alunos a um tema de cunho filosófico. Para os autores, "há que [se] 'insinuar' o filosófico, a interrogatividade da filosofia e a pertinência dessa interrogatividade no não-filosófico" (GRÁCIO; DIAS, 2004, p.7).

A necessidade de se induzir o filosófico nas aulas do ensino médio demanda, por si mesma, a criatividade na escolha ou até mesmo na construção dos recursos não filosóficos destinados a sensibilizar os alunos para determinados temas que admitem ou, às vezes, reclamam um enfrentamento filosófico. Quanto a essa utilização propedêutica do não-filosófico nas aulas de filosofia, Silvio Gallo (2006, p.27) sugere:

Penso que essa primeira etapa pode ser bem sucedida com o recurso a peças artísticas: uma música, um poema, um quadro, um conto, um filme; ou mesmo um desenho animado, uma história em quadrinhos... Em suma, algo que chame a atenção dos estudantes, sobretudo por falar sua própria linguagem, e que desperte seu interesse por um determinado problema.

A etapa posterior, para a qual se ordena a sensibilização, é a problematização. Neste estádio da aula, o objetivo é transformar em problema o tema para o qual o interesse e a atenção dos alunos foram despertos. O filósofo brasileiro propõe que essa problematização se refira a vários aspectos dos temas selecionados e se dê sob várias perspectivas, 
afinal, trata-se do momento em que "[...] estimulamos o sentido crítico e problematizador da filosofia, exercitamos seu caráter de pergunta, de questionamento, de interrogação" (GALLO, 2006, p.28); e essa interrogatividade que é própria à filosofia é capaz não só de "[...] despertar no aluno uma atitude 'crítica, racional e dialogante", mas também “[...] de fazer da educação filosófica no ensino secundário um espaço privilegiado da educação para a cidadania e a democracia" (GRÁCIO; DIAS, 2004, p.6, grifo do autor).

O passo seguinte, a investigação, consiste em buscar na história da filosofia ferramentas que, posteriormente, permitirão equacionar os problemas formulados na etapa anterior. $\mathrm{Na}$ investigação, os alunos são postos em contato com o arcabouço conceitual de que a filosofia dispõe para a interpretação dos mais diversos problemas que se apresentam na realidade. Conforme Silvio Gallo (2006), a visita à história da filosofia como meio de apreciar um problema propicia ao aluno uma visão particular da filosofia, ao passo que as várias revisitas, mediadas pelos vários problemas a serem propostos em aula, ensejarão uma visão mais abrangente e de conjunto da história da filosofia.

Por fim, a última etapa de trabalho nessa oficina de conceitos consiste - como o próprio nome sugere na conceituação, isto é, na utilização do instrumental conceitual adquirido na etapa anterior com vistas a equacionar os problemas levantados em aula, seja por meio da recriação daqueles conceitos, seja até mesmo pela criação de novos conceitos, o que se constitui como 
o exercício filosófico propriamente dito (GALLO, 2006). No tocante a esse fazer filosófico condicionado pela aula de filosofia tomada como uma oficina de conceitos, o pensador brasileiro sublinha que nem a recriação, nem a criação de conceitos são tarefas irrealizáveis. Mencionando Nietzsche e Deleuze e Guattari, Silvio Gallo (2006) afirma que o simples deslocamento de um conceito de seu contexto original para o contexto do problema investigado configura já uma recriação, pois o conceito, fora de seu uso originário, já não permanece mais o mesmo.

Que fique claro então que a criação (ou recriação) do conceito não é uma tarefa impossível: não se cria no vazio, a partir do nada; são os próprios conceitos, colhidos na história da filosofia, ou seus elementos próprios, que nos darão a matéria-prima para nossa atividade de criação ou recriação a partir de nosso próprio problema (GALLO, 2006, p.29).

\section{CONCLUSÃ0}

Do exposto no presente artigo, colige-se que, não obstante seja possível definir a filosofia de maneira diversa, se se aquiesce com a definição deleuzo-guattariana de que a filosofia é uma atividade per se criativa, cuja especificidade consiste na criação de conceitos sempre novos, então o ensino da filosofia, nomeadamente no escopo da educação básica, deve estar necessariamente fundamentado no cânone da criatividade, por cujo ditame devem se orientar todas as metodologias e estratégias do professor. 


\section{NOTAS}

${ }^{1}$ Graduando do curso de Filosofia da Universidade Federal de Uberlândia (UFU); bolsista de iniciação à docência no Programa Institucional de Bolsa de Iniciação à Docência (PIBID), subprojeto Filosofia. Email: victortotustuusmariae@gmail.com.

${ }^{2}$ Heidegger (2005, p.30) sublinha que quando nos perguntamos "o que é?" (neste caso, deve haver o destaque seja por itálico, seja por aspas, por se tratar de metalinguagem) "[...] não apenas aquilo que está em questão, a filosofia, é grego em sua origem, mas também a maneira como nos perguntamos, mesmo a nossa maneira atual de questionar ainda é grega”. Quando se pergunta o que é (ti estin) aquilo que designamos filosofia a questão aproxima-se, automaticamente, daquela maneira de questionar desenvolvida por Sócrates, Platão, Aristóteles (HEIDEGGER, 2005). Por isso, na perspectiva heideggeriana, a pergunta o que é? possui um caráter essencialmente filosófico.

${ }^{3}$ Retornar-se-á a essa questão no item II tão logo for apresentada a resposta de Deleuze e Guattari à pergunta “o que é a filosofia?".

${ }^{4}$ Cf. nota 2.

${ }^{5}$ Acerca da propositura kantiana de que a filosofia não pode ser aprendida (porque não pode ser ensinada), Rui Grácio e Sousa Dias (2004, p.5) explicam que isso ocorre porque "a Filosofia" enquanto tal não existe; apenas existem as mais diversas doutrinas filosóficas: "Tomada em si mesma, como um domínio particular de cognição, a filosofia é inensinável. Porquê? Porque não existe. Ora, o que não existe não pode, como é óbvio, ser ensinado. Já Kant afirmava - e a situação, como sabemos, não se alterou com ele ou depois dele - que para ensinar filosofia seria preciso primeiro que existisse A filosofia como coisa distinta das doutrinas filosóficas. Ora o que há, o que sempre houve e haverá, é a pluralidade dessas doutrinas ou, antes, a pluralidade do que elas corporizam: dos problemas, das teses e dos conceitos, sempre específicos (relativos a uma filosofia) introduzidos pelos filósofos".

${ }^{6} \mathrm{Há}$, porém, aqueles que não aquiescem com a ideia do "ensinar a filosofar” aplicada à prática escolar. Rui Grácio e Sousa Dias (2004, p.6), por exemplo, se opõe diametralmente a essa concepção, pois, na visão 
dos autores, "dar-se como objectivo pedagógico 'ensinar a filosofar' afigura-se-nos pretensioso, de sucesso mais do que improvável, se se tiver em conta o conflito, por assim dizer, entre as exigências próprias do filosofar e o exigível aos nossos aprendizes: se se tiver em conta a abstracticidade das experiências 'conceptivas' que definem o filosofar, a prática genuína da filosofia, de todo em todo estranhas aos interesses 'naturais' (psicologicamente naturais) dos nossos muito jovens alunos, adolescentes ainda. Não podemos crer que [...] haja alguém que tenha a veleidade de conseguir com os seus alunos, por mais excelentes que sejam, 'filosofar', 'fazer filosofia'. Todos sabemos que não é nunca disso que se trata, excepto para quem quisesse dar do filosofar a mais maltrapilha das imagens, pseudosocrática, de mera discussão de opiniões (por mais 'crítica' que a discussão se pretenda)".

\section{REFERÊNCIAS}

ASPIS, R. P. L. O professor de filosofia: o ensino de filosofia no ensino médio como experiência filosófica. In: Cad. Cedes, Campinas, v. 24, n. 64, set./dez. 2004, p.305-320.

AZEREDO, J. L. de. O papel da história da filosofia no ensino médio: uma interrogação a partir de Deleuze. In: SABERES, Natal - RN, v. 1, n.6, fev. 2011, p.35-52.

DELEUZE, G.; GUATTARI, F. O que é a filosofia? Rio de Janeiro: Ed.34, 1992. Tradução Bento Prado Jr. e Alberto Alonso Muñoz.

GALLO, S. A filosofia e seu ensino: conceito e transversalidade. In: Ethica, Rio de Janeiro, v. 13, n. 1, 2006, p.17-35. 
GALLO, S. A. O que é a Filosofia da Educação? Anotações a partir de Deleuze e Guattari. In: Perspectiva, Florianópolis, v. 34 , n. 18 , julh./dez. 2010, p.49-68.

GOUHIER, H. La Philosophie et son Histoire. Paris: J. Vrin, 1947.

GRÁCIO, R. A.; DIAS, S. Ensi(g)nar Filosofia? 2004. Disponível em: $<$ http://www.apfilosofia.org/documentos/ pdf/RuiGracioeSousaDias_ENSIgnar.pdf.> Acesso em: 10 mai. 2016.

HEIDEGGER, M. Qu'est-ce que la philosophie? In:

Martin Heidegger: conferências e escritos filosóficos. São Paulo: Nova Cultural, 2005. Tradução e notas de: Ernildo Stein. p 27-40.

KANT, I. Crítica da Razão Pura. 5. ed. Lisboa: Fundação Calouste Gulbenkian, 2013. Tradução Manuela Pinto dos Santos e Alexandre Fradique Morujão.

RUSSELL, B. Os Problemas da Filosofia. Florianópolis, 2005. Tradução Jaimir Conte. Disponível em <http://conte.prof. ufsc.br/russell.html>. Acesso em: 13 jun. 2015.

ZOURABICHVILI, F. O vocabulário de Deleuze. Rio de Janeiro, 2004. Tradução André Telles. Disponível em: $<$ http://claudioulpiano.org.br.s87743.gridserver.com/ wpcontent/uploads/2010/05/deleuze-vocabulario-francoiszourabichvili1.pdf>. Acesso em: 13 jun. 2015. 